\title{
Linaclotide: A new drug for the treatment of chronic constipation and irritable bowel syndrome with constipation
}

United European Gastroenterology Journal 1(1) 7-20

(C) Author(s) 2013

Reprints and permissions: sagepub.co.uk/journalsPermissions.nav DOI: $10.1177 / 2050640612474446$ ueg.sagepub.com

(3)SAGE

\author{
Maura Corsetti and Jan Tack
}

\begin{abstract}
Introduction: Linaclotide is the first member of a novel class of drugs to be extensively evaluated for the treatment of chronic constipation (CC) and irritable bowel syndrome with constipation (IBS-C).

Aim: To provide a comprehensive overview of the current state of knowledge on linaclotide, its pharmacological properties, mode of action and efficacy in clinical trials to date.

Methods: We conducted a systematic review of the literature.

Results: The survey revealed that linaclotide is a minimally absorbed, 14-amino acid peptide which acts in the intestinal lumen on guanylate cyclase-C (GC-C). This results in generation of cyclic guanosine monophosphate (cGMP), which stimulates chloride secretion, resulting in increased luminal fluid secretion and an acceleration of intestinal transit. In animal models, linaclotide also decreased visceral hypersensitivity. Linaclotide softened stool and increased transit in CC and in IBS-C. Phase II and phase III clinical studies established efficacy of linaclotide in CC (linaclotide $145 \mu \mathrm{g}$ daily approved in the United States for CC) and in IBS-C (linaclotide $290 \mu$ g daily US Food and Drug Administration-approved for IBS-C, with favourable recommendation for the European Medicines Agency Committee for Medicinal Products for Human Use (CHMP). Linaclotide showed a favourable safety profile, and the main treatment-emerging adverse event was diarrhea, leading to discontinuation rates of up to $5 \%$. Linaclotide is an important addition to the therapeutic possibilities for treating IBS-C and CC.
\end{abstract}

\section{Keywords}

Linaclotide, guanylate cyclase-C, colonic transit, visceral hypersensitivity, irritable bowel syndrome, chronic constipation, phase II and phase III studies

Received: 23 November 2012; accepted: 14 December 2012

\section{Introduction}

Chronic constipation (CC) is a highly prevalent condition. A systematic review and meta-analysis of available epidemiological studies have estimated the population prevalence to be as high as $14 \%$, with the lowest rates occurring in South East Asia. ${ }^{1} \mathrm{CC}$ is more prevalent in women and increases with age and lower socio-economic status. ${ }^{1,2}$ The Rome III consensus definition of functional CC is summarized in Table $1 .{ }^{3} \mathrm{CC}$ is associated with an increased health care cost and an increased level of loss of work productivity and activity impairment. ${ }^{4-7} \mathrm{CC}$ is characterized by infrequent bowel movements, hard stools and straining when passing stool, often in combination with abdominal discomfort, bloating, cramps and pain. ${ }^{2}$

The majority of subjects with CC self-manage their constipation, mainly using lifestyle (dietary) adjustments and over-the-counter laxatives. ${ }^{8-10}$ In those seeking medical attention, after appropriate diagnostic work-up, laxatives (over-the-counter or prescription) are the recommended initial approach. ${ }^{11,12}$ For a large number of patients, the use of laxatives does not result in sufficient control of constipation and its associated symptoms, lacks predictability or is associated with adverse effects or poor tolerance. ${ }^{8,9,12}$. Hence, a substantial unmet need persists in the treatment of CC.

In a considerable group of patients, chronic constipation overlaps with symptoms of irritable bowel

TARGID (Translational Research Center for Gastrointestinal Disorders), University of Leuven, Leuven, Belgium

Corresponding author:

Jan Tack, TARGID, Herestraat 49, B-3000 Leuven, Belgium.

Email: jan.tack@uzleuven.be 
Table 1. Rome III criteria for chronic constipation and for IBS with constipation

Rome III criteria for chronic constipation ${ }^{a}$

1. Must include two or more of the following:

a. Straining during at least $25 \%$ of defecations

b. Lumpy or hard stools in at least $25 \%$ of defecations

c. Sensation of incomplete evacuation for at least $25 \%$ of defecations

d. Sensation of anorectal obstruction/blockage for at least $25 \%$ of defecations

e. Manual maneuvers to facilitate at least $25 \%$ of defecations (e.g. digital evacuation, support of the pelvic floor)

f. Fewer than three defecations per week

2. Loose stools are rarely present without the use of laxatives

3. Insufficient criteria for irritable bowel syndrome

Rome III criteria for IBS with constipation ${ }^{\text {b }}$

Recurrent abdominal pain or discomfort ${ }^{\mathrm{c}}$ at least three days/month in the last

three months associated with two or more of the following:

1. Improvement with defecation

2. Onset associated with a change in frequency of stool

3. Onset associated with a change in form (appearance) of stool

Hard or lumpy stools (Bristol Stool Scale 1 or 2) $>25 \%$ and loose (mushy) or watery stools (Bristol Stool Scale 6 or 7)

$<25 \%$ of bowel movements.

${ }^{a}$ Criteria fulfilled for the last three months with symptom onset at least six months prior to diagnosis.

${ }^{b}$ Criterion fulfilled for the last 3 months with symptom onset at least 6 months prior to diagnosis.

c"Discomfort" means an uncomfortable sensation not described as pain.

In pathophysiology research and clinical trials, a pain/discomfort frequency of at least 2 days a week during screening evaluation is recommended for subject eligibility.

syndrome (C-IBS). Irritable bowel syndrome (IBS) is a lower functional gastrointestinal disorder affecting up to $15 \%$ of the general population in Western countries. ${ }^{13}$. It is characterized by unexplained abdominal pain, discomfort, and bloating in association with altered bowel habits. The Rome III consensus definition of C-IBS is summarized in Table $1{ }^{3}$ Traditional C-IBS therapies are mainly directed at the relief of individual symptoms - for example, laxatives for constipation or smooth-muscle relaxants for pain. They are often less efficacious in addressing the overall symptom complex. ${ }^{14}$

A number of new non-laxative medications have recently been demonstrated to be more effective than placebo in treating $\mathrm{CC}$, including two segretagogues, lubiprostone and linaclotide. ${ }^{10}$ Lubiprostone is the first chloride-channel activator to gain regulatory approval in the United States and in clinical trials it has been demonstrated to significantly increase the stool frequency, reduce stool consistency and straining relative to placebo in $\mathrm{CC}$ patients and also to reduce abdominal pain and improve bowel function in CIBS. ${ }^{15-18}$ The drug is not currently approved in Europe and the main side effect, nausea, is often mild and transient, leading to withdrawal in $5 \%$ of patients.

Linaclotide is the first orally administered 14-aminoacid peptide of the guanylin peptide family, which increases intestinal secretion through the activation of guanylate cyclase $\mathrm{C}(\mathrm{GC}-\mathrm{C})$ and has been demonstrated to be effective in treating both patients with $\mathrm{CC}$ and with C-IBS. ${ }^{19-25}$ Linaclotide has recently been approved in the United States for the treatment of CC and IBS-C, and in Europe for the treatment of C-IBS. This review focuses on the pharmacology, efficacy and safety profile of linaclotide. We conducted a search of literature on linaclotide using Pubmed, ISI Web of Knowledge and clinical trials registries available on the Internet.

\section{Basic pharmacology}

GC-C is a soluble and single-membrane-spanning enzyme expressed on the luminal surface of intestinal epithelial cells, where its activation regulates chloride secretion. Heat-stable enterotoxins (STs) from pathologic strains of Escherichia coli were the first natural ligands shown to activate GC-C. ${ }^{26,27}$ The first endogenous ligand of GC-C was identified in $1992 .{ }^{28}$ The mature form of the peptide called guanylin is a 15-amino-acid peptide that contains two intra-molecular disulfide bonds. A second 19-amino-acid endogenous GC-C ligand with conserved disulfide bonds to guanylin was purified from urine and named uroguanylin. ${ }^{29}$ Human guanylin and uroguanylin are about $50 \%$ identical. ST contains three disulfide bonds and its affinity for GC-C is 10 and 100 times higher than the affinity of, respectively, uroguanylin and guanylin, which only have two disulfide bonds. Linaclotide is a 13-residue truncated homolog of ST that contains two amino acid substitutions, which maintain maximal potency while improving resistance to proteolytic degradation. ${ }^{30}$ 
Guanylin and uroguanylin are released in an autocrine and paracrine fashion into the intestinal lumen and they function as endocrine hormones regulating ion transport in extra-intestinal epithelia (e.g. the kidney). Uroguanylin elicits its activity primarily in the acidic environment of the proximal duodenum, while guanylin is more active in parts of the intestinal tract with more neutral $\mathrm{pH}^{31}$ Both the endogenous peptides and ST stimulate GC-C, thereby increasing the production of the second messenger cyclic guanosine 3',5'-monophosphate (cGMP), which is involved in the regulation of a broad range of physiological process, including the activation of the cGMP-dependent protein kinases II (PGKII). The PGKII regulates the activity of the cystic fibrosis transmembrane conductance regulator (CFTR), an ion-channel protein co-localized with CFTR at the apical surface of intestinal epithelial cells and involved in regulating intestinal fluid homeostasis (Figure 1).

Measuring the affinity of linaclotide for GC-C receptor on human colon carcinoma cell line T84, which is known to express this receptor, it has been demonstrated that linaclotide inhibits the binding of a competitive ligand (STa) in a concentration-dependent manner at $\mathrm{pH}$ 7, resulting in a two-site binding model, with a calculated $\mathrm{Ki}$ for linaclotide of $1.24 \pm 0.63 \mathrm{nM}$ for the high affinity and of $122 \pm 35 \mathrm{nM}$ for the low affinity site. ${ }^{31,32}$ In contrast to what was observed for guanylin and uroguanylin, the binding affinity of linaclotide to the GC-C receptor on T84 cells is similar at $\mathrm{pH} \mathrm{5,} \mathrm{at} \mathrm{pH} 8$ and $\mathrm{pH} 7$. Linaclotide also inhibits the binding of the same ligand, STa, to the GC-C receptor on rat intestinal mucosal cells in a concentration-dependent manner with a $\mathrm{Ki}$ of $4.2 \pm 0.98 \mathrm{nM}$, and with a binding curve fitting with a one-site model.

As for guanylin and uroguanylin, linaclotide stimulates the production of intracellular cGMP in human T84 cells in a concentration-dependent manner with a significant difference compared to the two peptide hormones at the concentration of $>1 \mathrm{nM} .^{31,32}$ The concentration of GC-C receptor agonist that produces $50 \%$ of the maximal activity (EC50) of linaclotide at $\mathrm{pH} 7$ $(99 \pm 17.5 \mathrm{nM})$ is $8-10$-fold more potent than that of guanylin and uroguanylin at the same $\mathrm{pH}$ $(970 \pm 236 \mathrm{nM}$ and $798 \pm 217 \mathrm{nM})$. Using mice genetically deficient for $\mathrm{GC}-\mathrm{C}$ gene, it has been confirmed that this trans-membrane enzyme is the molecular target for all the observed effects of linaclotide.

\section{Pharmacokinetics}

Pharmacokinetic analysis in vivo in rats has demonstrated that linaclotide is only minimally absorbed after $10 \mathrm{mg} / \mathrm{kg}$ oral dosing, as demonstrated by the area under the curve (AUC) (0-6h) of $18.800 \mathrm{ng}-\mathrm{h} / \mathrm{ml}$ after intravenous administration of $10 \mathrm{mg} / \mathrm{kg}$ and the AUC (0-6 h) of $19.7 \mathrm{ng}-\mathrm{h} / \mathrm{ml}$ after oral administration, with a resulting oral bioavailability of $0.1 \% .^{31,32}$ Less than $1 \%$ of the orally administered dose is recovered in the feces in the first 24 hours. ${ }^{33}$

Since linaclotide is minimally absorbed into the systemic circulation and the majority of drug is not excreted in the feces, a series of in vitro and in vivo experiments were conducted in rodents and in human biomaterials from cadavers. These demonstrated that linaclotide undergoes proteolytic digestion in the gastrointestinal tract. ${ }^{33}$ Under non-reducing conditions, linaclotide's stability and resistance to enzymatic hydrolysis by pepsin, trypsin, aminopeptidase or chymotrypsin had been demonstrated in rats in vitro after 3 hours of incubation in simulated gastric fluid $(\mathrm{pH} 1) .{ }^{31}$ The first part of degradation involves the proteolytic removal of its Cterminal tyrosine which is not protected by the disulfide bonds by carboxy-peptidase $\mathrm{A}$ in the duodenum and in the jejunum, resulting in the formation of a 13-aminoacid metabolite, MM-419447 (Des-Tyr14). ${ }^{33}$ The second part of degradation takes part in the intestine, where both linaclotide which escaped the first proteolytic process and the active metabolite undergo reduction of disulfide bonds. This process leaves both linaclotide and MM-419447 highly susceptible to proteolytic degradation, which converts them to small-fragment nonactive peptides and amino acids, which are then absorbed through the intestine. ${ }^{33}$

After oral dosing, systemic exposure to linaclotide and MM-419447 is minimal, and the majority of the plasma, whether sampled from the jugular or portal vein, has concentrations of these substances that are below the quantitation limits of $1 \mathrm{ng} / \mathrm{ml}$ (linaclotide) and $2 \mathrm{ng} / \mathrm{ml}$ (MM-419447). ${ }^{33}$ In the systemic circulation (jugular vein), the maximum observed linaclotide and metabolite plasma concentrations (Cmax) were, respectively, $2.97 \mathrm{ng} / \mathrm{ml}$ and $2.28 \mathrm{ng} / \mathrm{ml}$, and the time to reach the maximum observed plasma concentration (Tmax) was 5 minutes for each. By 40 minutes, systemic plasma concentrations were below the lower limits of quantification for both linaclotide and the metabolite. More than $95 \%$ of the quantity of active peptide recovered in the feces is represented by MM-419447, which has the same pharmacological and pharmacokinetics properties as linaclotide. ${ }^{33}$

In a phase I, food-effect US study, plasma samples from fed and fasted subjects dosed with $290 \mu \mathrm{g}$ of linaclotide once daily for seven days showed no quantifiable concentrations of linaclotide or MM-419447. When linaclotide was administered as a single 10x dose $(2,897 \mathrm{ng})$ on the eighth day, linaclotide concentrations were quantifiable in plasma from two of the 18 subjects (both fasted), and MM-419447 was not 


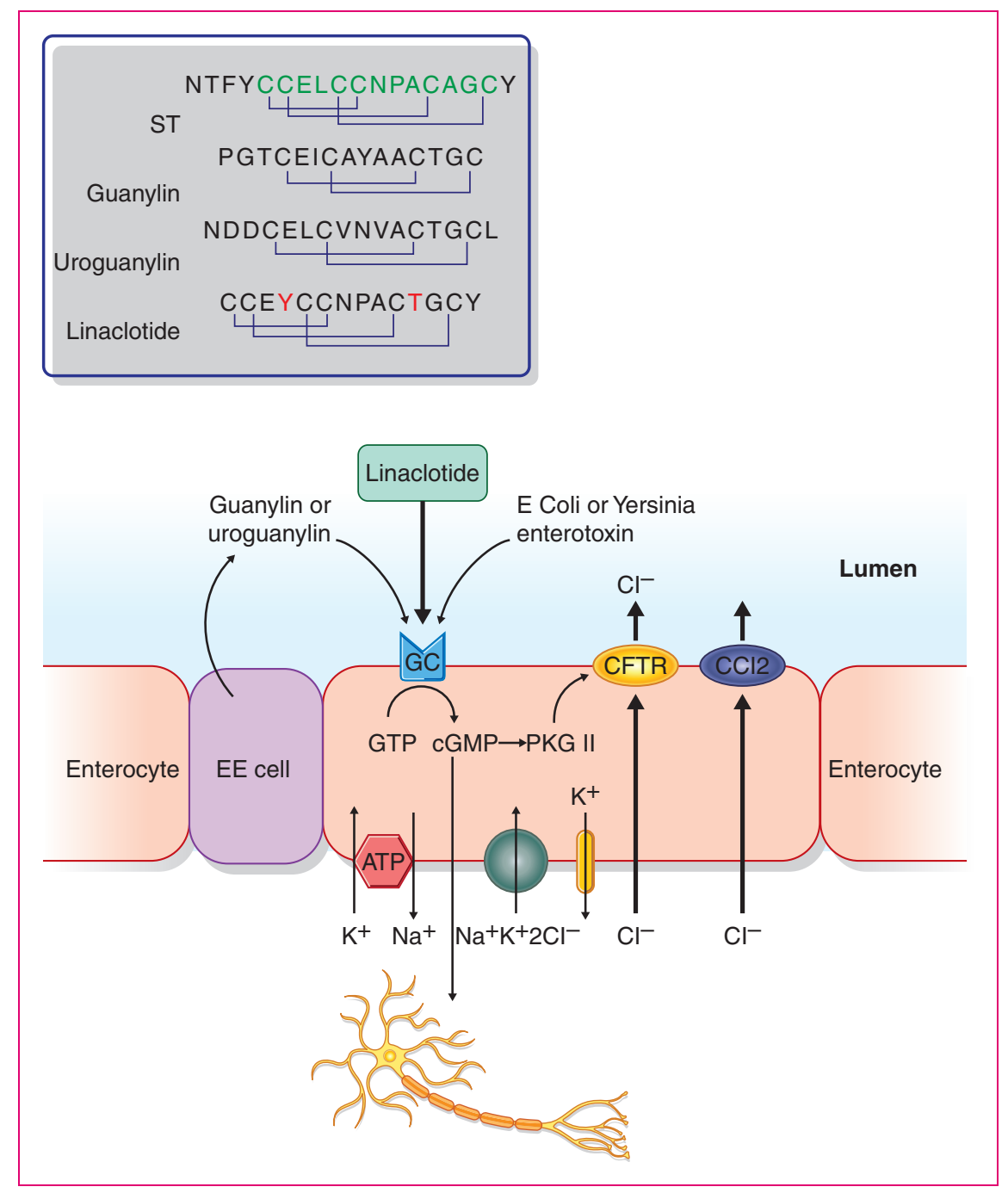

Figure 1. Schematic representation of the actions of linaclotide and other ligands through the guanylate cyclase $\mathrm{C}$ receptor on enterocytes. EC cell: entero-endocrine cell; ST: heat-stable enterotoxin; CFTR: cystic fibrosis trans-membrane conductance regulator; CCI2: chloride channel type 2; GTP: guanosine triphosphate; cGMP: cyclic guanosine 3',5'-monophosphate; PKG: cGMP-dependent protein kinase.

detectable in the plasma of any subjects. In the four phase III trials in patients with CC and C-IBS, plasma was sampled on day 1 and day 29 in 465 out of 1654 patients who received either $290 \mu \mathrm{g}(N=313)$ or $145 \mu \mathrm{g}$ $(N=152)$ of linaclotide. Only two patients (both of whom received the $290 \mu \mathrm{g}$ dose) had measurable plasma concentrations of linaclotide, each $<0.5 \mathrm{ng} / \mathrm{ml}$, and none of the 465 patients had measurable plasma concentrations of MM-419447. In the phase I foodeffect study, stool samples were collected during the second period of dosing from fed and fasted subjects following oral administration of $290 \mu \mathrm{g}$ of linaclotide once daily for seven days and then again following the administration of a single 10x dose on the eighth day. Recovery of active peptide ranged from 0 to $20 \%$ of the dose with a mean of $3-5 \%$ of dosed linaclotide. Virtually all of the recovered active peptide was MM-419447. Linaclotide was found in the stool samples from subjects only after administration of the $2897 \mu \mathrm{g}$ dose in the fed state; these three subjects had a median of $0.4 \%$ of dosed linaclotide in their stool. The amount of total recovered active peptide was similar in fed and fasted subjects.

\section{Pharmacodynamics}

\section{Preclinical studies}

Linaclotide and intestinal secretion. Similarly to what was observed for STa, in vivo activation of GC-C after injection of linaclotide $(5 \mu \mathrm{g})$ into surgically ligated rat 
duodenal, jejunal and ileal loops induces a significant increase in the volume of luminal fluid in all the loops and an increase of the concentration of secreted cGMP, which is significant in the duodenum and in the jejunum but not the ileum. As confirmed by the use of mice genetically deficient for GC-C gene, this trans-membrane receptor is the molecular target for all the observed effects of linaclotide. ${ }^{31-33}$

Linaclotide and gastrointestinal transit. The effect of acute dose of linaclotide on gastrointestinal transit has been assessed in rats by measuring the distance traveled by the charcoal front after 10 minutes as percentage of total small intestine length. All rats that received linaclotide at the doses of $5,10,20 \mu \mathrm{g} / \mathrm{kg}$ displayed a significant increase in the gastrointestinal transit rate compared to the vehicle-treated rats. When the same experiment was repeated in wt and GC-C null mice, a dose of $100 \mu \mathrm{g} / \mathrm{kg}$ of linaclotide significantly increased the gastrointestinal transit rate in wt mice compared to the vehicle wt-treated mice, while no differences were observed between linaclotide and vehicle-treated null mice. ${ }^{31-33}$

Linaclotide and modulation of visceral sensitivity. A potential effect of linaclotide in modulating visceral sensitivity has been investigated in an in vivo study on animal models. ${ }^{34}$ The effect of GC-C activation on visceral hyperalgesia was tested in three different rodent models. These models comprised colonic hyperalgesia after the induction of inflammatory colitis by intracolonic administration of trinitrobenzenesulfonic acid (TNBS), and stress-induced colonic hyperalgesia induced by acute restraint and water avoidance stress (WAS). In addition, the role of GC-C receptor activation in the modulation of sensory response to distension has been evaluated in the model of TNBS-induced visceral hyperalgesia in male wild-type (wt) and in GC$\mathrm{C}$ null mice.

The results demonstrated that, prior to the administration of linaclotide or vehicle, in the inflammatory model of TNBS-induced colitis the mice were hypersensitive only to low distending pressures, in the model of acute restraint stress to both high and low distending pressures, while in the WAS model only to high distending pressures. The oral administration of linaclotide did not affect the response to colo-rectal distension under basal conditions, while reducing the hypersensitivity to distension in all the different experimental conditions. The effect of linaclotide was evident only at low doses $\left(\leq 3 \mu \mathrm{gkg}^{-1}\right)$, while at higher doses $\left(\geq 10 \mu \mathrm{gkg}^{-1}\right)$ it either did not affect the sensory response to distension or, in the WAS model, even increased the colorectal hypersensitivity. Under basal conditions colorectal sensitivity to distension was lower in GC-C null mice than in wt mice, while after TNBS instillation both wt and null mice developed hypersensitivity to colorectal distension, but linaclotide only reversed the sensory response in wt mice and not in GC-C null mice. $^{34}$

The results after administration of linaclotide suggest that GC-C activation is involved in the modulation of sensory response to distension only in the presence of hypersensitivity. However, these results are in contrast with those of null mice for GC-C which suggest that activation of the GC-C receptor may play a role in mechanosensitivity under basal conditions whereas it is not involved in the development of colo-rectal hypersensitivity. The mechanism by which linaclotide modulates the sensory response to distension is unclear, but the different result in basal conditions and in models of hypersensitivity could be related to the effect of the action of GC-C agonists at the level of the different mechanoreceptors. Indeed, two recent preliminary in vitro studies ${ }^{35,36}$ have evaluated the effect of linaclotide $(1,30,100,300,1000 \mathrm{nM})$ and of other two GC-C agonists $\operatorname{STc}(1,50,250,1000 \mathrm{nM})$, and uroguanylin $(30,100,300,1000,3000 \mathrm{nM})$ individually applied on mucosal surface, on mechanosensory responses of colorectal splanchnic high-threshold nociceptors and of pelvic low-threshold mucosal afferents both in healthy conditions and in a model of chronic visceral hypersensitivity $(\mathrm{CVH})$. The effect of the three GC-C agonists has been investigated in healthy mice and at 28 days post-TNBS administration, when inflammation had resolved and nociceptors were mechanically hypersensitive. Both in healthy conditions and during $\mathrm{CVH}$, linaclotide, STc and uroguanylin dose-dependently reduced nociceptor mechanosensitivity. In contrast, STc increased the low-threshold pelvic mucosal afferent mechanosensitivity in healthy mice but not in CVH. Similar results were observed in another preliminary study $^{37}$ applying cGMP, the suggested mediator of linaclotide function on visceral sensitivity, ${ }^{33}$ in the same model and on the same splanchnic nociceptors and pelvic low-threshold afferents. Taken together, all these results suggest a role of GC-C activation in the modulation of nociception mainly in hypersensitive conditions and also of mechanosensitivity of lowthreshold mucosal afferents in basal conditions. These effects, if confirmed in humans, could be useful for improving the co-ordination of defecation in patients without and for reducing pain in those with visceral hypersensitivity. The different effects of low and high dose of linaclotide on sensory response to distension observed in studies in vivo on animals could suggest that at high doses linaclotide loses pharmacological specificity, and this could potentially be related to cGMP acting upon other signaling pathways. Alternatively, as previously suggested by Tonini 
et al. ${ }^{38}$ for another poorly absorbed drug, tegaserod, it is possible that at high doses linaclotide could be gradually absorbed, possibly acting on GC-C on other locations or on autoreceptors. Further studies should clarify these aspects.

\section{Human studies}

Linaclotide and indirect measure of effect on intestinal transit. In one placebo-controlled, double-blind, randomized, phase I study in 48 healthy subjects examining the effect of multiple ascending oral doses $(30,100,300$, $1000 \mu \mathrm{g})$, linaclotide has been demonstrated to decrease stool consistency, to improve the ease of stool passage (at the dose of $1000 \mu \mathrm{g}$ ), to increase stool frequency and stool weight. In this study linaclotide was well tolerated, without any serious side effects at any dose. ${ }^{33}$

\section{Clinical studies}

\section{Chronic idiopathic constipation}

In a multicenter, randomized, double-blind, placebocontrolled pilot study, the safety, tolerability and exploratory efficacy of 100,300 and $1000 \mu$ g linaclotide once daily for two weeks were tested in $42 \mathrm{CC}$ patients without a history of pelvic floor dysfunction, the majority of which were females. ${ }^{19}$ Linaclotide produced a dose-dependent increase of weekly complete spontaneous bowel movements (SBMs) and stool consistency compared to placebo. Linaclotide $100 \mu \mathrm{g}$ was significantly more effective than placebo in increasing bowel frequency, while linaclotide $1000 \mu \mathrm{g}$ significantly decreased stool consistency and improved straining. In this study linaclotide also demonstrated a significant effect on abdominal discomfort compared to placebo. Diarrhea was the more common adverse event reported by patients treated with linaclotide compared to those treated with placebo. Only in one patient did diarrhea, scored as moderate intensity, lead to discontinuation of linaclotide.

In a subsequent multicenter, double-blind, placebocontrolled, parallel group, dose range-finding phase II study, the effect of $75,150,300$ and $600 \mu \mathrm{g}$ of oral linaclotide was tested in $310 \mathrm{CC}$ patients without a history of pelvic floor dysfunction for four weeks. ${ }^{20}$ The majority of patients were females. All doses of linaclotide increased the frequency of SBMs and of complete SBMs (CSBMs), improved stool consistency, straining, abdominal discomfort, bloating, global assessment and quality of life. Again, the only more commonly observed adverse event with linaclotide was diarrhea, with six patients discontinuing the treatment due to diarrhea (three on $600 \mu \mathrm{g}$; diarrhea rated as severe in two of these). The efficacy of linaclotide generally increased with increasing dose, except for abdominal discomfort and bloating. The authors speculate that this result may be a consequence of a low baseline score of these symptoms. On the other hand, this result is in line with some observations in in vivo animal studies, where the higher doses of linaclotide did not show anti-hyperalgesic effects. Significant benefit was obtained for all end points with doses of $150 \mu \mathrm{g}$ and higher, but the $600 \mu \mathrm{g}$ dose was associated with a higher prevalence of diarrhoea and a less consistent effect on pain and bloating.

The 150 and $300 \mu \mathrm{g}$ doses were selected for further development, but corrected to 145 and $290 \mu \mathrm{g}$, reflecting improved methods used to measure linaclotide content in the capsules. Hence, the numerical dose adjustment does not reflect changes in the actual amount of linaclotide used in the studies. ${ }^{39}$ Two multicenter, double-blind, placebo-controlled, parallel group, dual-dose, phase III studies finally evaluated the effect of oral linaclotide $145 \mu \mathrm{g}$ and $290 \mu \mathrm{g}$ for 12 weeks in $1276 \mathrm{CC}$ patients (study 303 and study 01 ). ${ }^{21}$ At the end of the 12-week treatment period, the patients in study 303 entered a four-week, double-blind period of randomized withdrawal (RW) to a once-daily regimen, in such way that patients who have received linaclotide during the preceding 12 -week period were randomly assigned to receive either linaclotide at the same dose or placebo, while patients who previously received placebo were assigned to $290 \mu \mathrm{g}$ of linaclotide (Figure 2A). The two studies were conducted in 204 clinical centers in the United States and eight clinical centers in Canada. To be eligible patients had to report less than three SBMs per week and have one or more of the following signs and symptoms during more than $25 \%$ of bowel movements for at least 12 weeks within the preceding 12 months: straining, lumpy or hard stool and a sensation of incomplete evacuation. Moreover, patients fulfilling the Rome II criteria for IBS or with a history of pelvic floor dysfunction had to be excluded. The majority of patients were females, with a mean number of SBMs of about two per week and of complete SBMs of about 0.3 per week with a constipation score of about 3 during the run-in period. The primary end point ( $>3$ complete SBM and an increase of $\geq 1$ complete SBM per week during at least 9 or 12 weeks) was reached by $21 \%$ and $16 \%$ of patients treated with linaclotide $145 \mu \mathrm{g}$ and by $19 \%$ and $21 \%$ of patients treated with linaclotide $290 \mu \mathrm{g}$ as compared to $3 \%$ and $6 \%$ with placebo, respectively in studies 303 and 01 (Figure 2B). Improvement in all secondary end points, including straining, stool consistency, abdominal discomfort, bloating and constipation severity, was significantly superior with linaclotide compared to placebo. Diarrhea was the more common adverse event in patients treated with linaclotide, leading to 


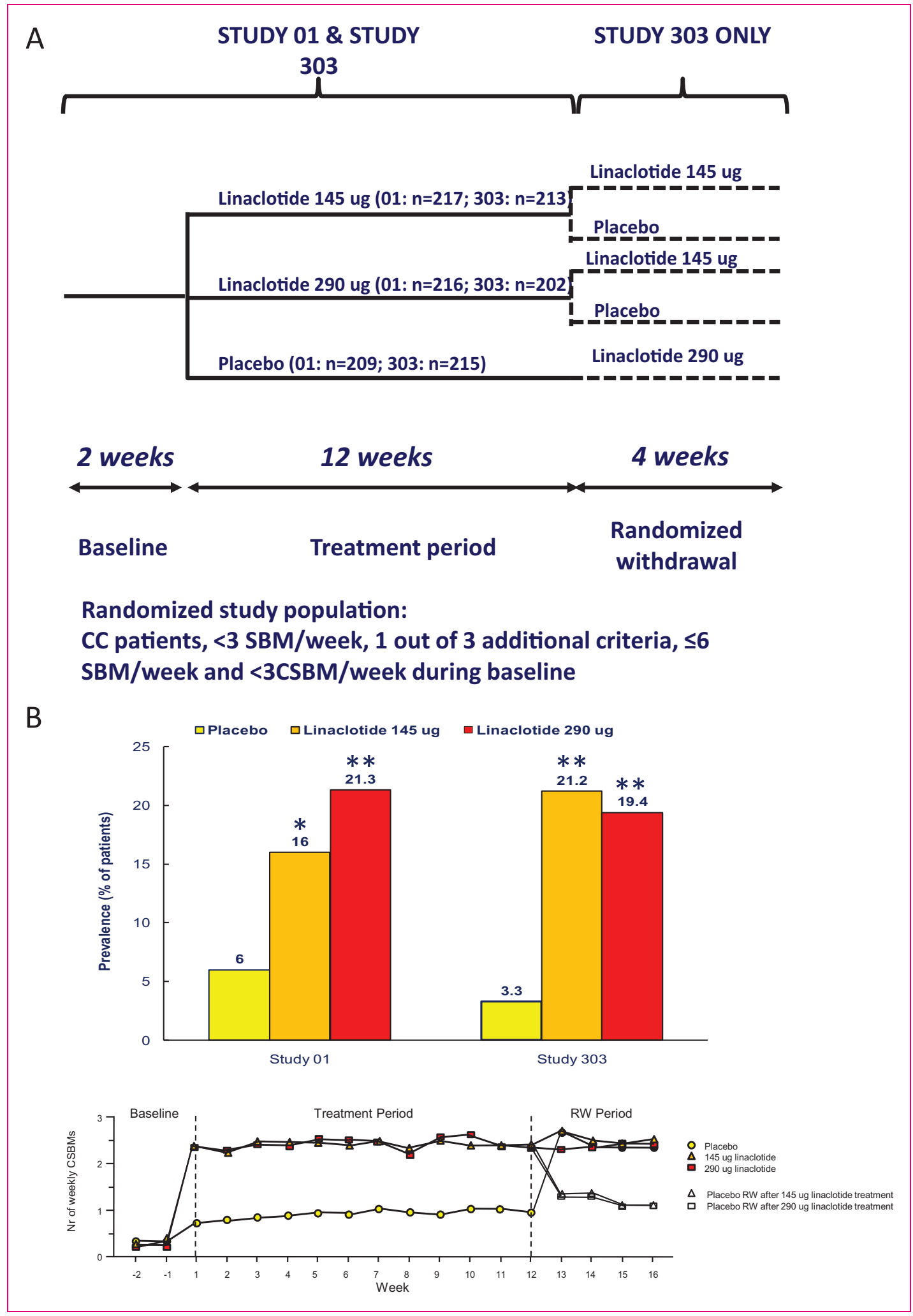

Figure 2. (A) Schematic outline of the phase III studies with linaclotide in chronic constipation (CC). SBM: spontaneous bowel movement; CSBM: complete spontaneous bowel movement. (B) Upper panel: responder rates to placebo and two doses of linaclotide in studies 01 and 303 in CC. Responders are defined as patients with a weekly frequency of $\geq 3$ CSBMs and an increase of $\geq 1$ CSBM from baseline for at least 9 weeks of the 12 -week treatment period. ${ }^{\star} p<0.01$ compared to placebo; ${ }^{\star \star} p<0.001$ compared to placebo. Lower panel: mean number of weekly CSBMs in trial 303 , according to the treatment phase, modified from Lembo et al. ${ }^{21}$ 
treatment discontinuation in about $4 \%$ of patients. The patients who continued to take linaclotide and those who switched to linacotide during the withdrawal period had a (sustained) response to linaclotide in increase of complete SBMs comparable with that obtained during the preceding 12-week treatment period, while those who switched from linaclotide to placebo had a decrease in complete SBMs. The effect of linaclotide was observed within the first 24 hours and was sustained through 16 weeks.

More than 1100 CC patients entered an open-label safety study of up to one year treatment with 145 or $290 \mu \mathrm{g}$ daily. The most frequently reported adverse event was diarrhea, occurring in $31.4 \%$ of the patients, and rated as severe in $3.4 \%$. No other major adverse events were noted. ${ }^{40,41}$

\section{Irritable bowel syndrome with constipation}

Phase II. The effect of oral linaclotide 100 and $1000 \mu \mathrm{g}$ once daily on colonic transit was first evaluated in a randomized, double-blind, placebo-controlled phase IIa study in 36 women with Rome II C-IBS, without evidence of evacuation disorders. ${ }^{42}$ Scintigraphyassessed colonic transit was normal in more than onehalf of patients. After five days of treatment, linaclotide resulted in a significant stimulatory effect on ascending colon emptying half-time and overall colon transit at 48 hours as compared to placebo, with a statistically significant effect of $1000 \mu \mathrm{g}$ but not of $100 \mu \mathrm{g}$. Linaclotide was also more effective than placebo in improving stool frequency, stool consistency and ease of passage.

In a subsequent randomized, multicenter, doubleblind, placebo-controlled phase II study, the effect of oral $75,150,300$ and $600 \mu \mathrm{g}$ linaclotide for 12 weeks was assessed in $420 \mathrm{C}$-IBS patients. ${ }^{22}$ To be eligible, patients had to fulfill the Rome II criteria for IBS and additional c-IBS criteria (one or more of (a) straining on at least $25 \%$ of bowel movements, (b) lumpy or hard stools in at least $25 \%$ of bowel movements or (c) sense of incomplete evacuation in at least $25 \%$ of bowel movements). In addition, during a two-week baseline period, patients were required to report a mean score of 2 or more for daily assessment of abdominal pain or discomfort on a $1-5$ scale, a mean of $<3$ CSBMs/week and $\leq 6 \mathrm{SBMs} /$ week. The majority of patients were females, had a mean number of SBMs of about three per week and of CSBMs of about 0.3 per week, with constipation and IBS severity scores, respectively, of 3.7 and 3.6 during run-in period. All doses of linaclotide significantly improved the frequency of CSBMs (the primary end point), severity of straining, stool consistency, abdominal pain, bloating and abdominal discomfort. The effect of linaclotide both on bowel function and abdominal symptoms was maximal at the dose of
$300 \mu$ g. Particularly, abdominal symptoms of pain, discomfort and bloating the efficacy did not increase with a dose increment from $300 \mu \mathrm{g}$ to $600 \mu \mathrm{g}$. The patients who reported severe or very severe abdominal pain (a score of 4 or 5) for at least $50 \%$ of days during the basal period demonstrated the greatest reduction in abdominal pain during the treatment period with linaclotide compared with placebo. Diarrhea was the most common and the only dose-dependent adverse event in patients treated with linaclotide, leading to treatment discontinuation in $4 \%$ of patients.

Phase III, FDA end points. The two phase III, placebocontrolled, randomized studies, which were the basis for the US Food and Drug Administration (FDA) approval of linaclotide in IBS-C, investigated the effect of oral once-daily linaclotide $(290 \mu \mathrm{g})$ for 12 weeks (study 31) and for 26 weeks (study 302), respectively, in 800 and 804 patients with C-IBS $(23,24)$ (Figure 3A). The two studies were conducted, respectively, in 118 outpatient clinical research centers (111 in the United States and 7 in Canada) and in 102 clinical centers in the United States. To be eligible, patients had to fulfil the Rome II criteria for C-IBS, and in the study 31 they were asked not to report a history of pelvic floor dysfunction. They were allowed to continue ongoing treatments for IBS that might induce constipation (e.g. tricyclic antidepressants) at a stable dose for at least 30 days before the screening visit, with no planned change in dosing after that visit. Moreover, in study 31 patients were allowed to continue on a stable regimen of fiber, bulk laxatives, stool softeners or probiotics. In study 31, patients who completed the entire12-week period were eligible to enter the doubleblind four-week randomized withdrawal (RW) period to assess the possible "rebound effect" of linaclotide. In both studies, the effect of linaclotide was assessed according to the recently finalised FDA guidance for IBS clinical trials. According to current "FDA interim endpoints for IBS-C ${ }^{, 43,44}$ a responder is defined as a patient who meets both of the following criteria in the same week for at least 6 of the 12 weeks of the treatment period: an improvement of $\geq 30 \%$ from baseline in the mean rating of daily worst abdominal pain scores, as well as an increase of $\geq 1$ complete SBM from baseline. In both studies three additional primary end points were also assessed, which required patients to meet the following weekly responder criteria for at least 9 out of the first 12 weeks of treatment period: an improvement of $\geq 30 \%$ from baseline in the average of daily worst abdominal pain scores; $\geq 3$ complete SBMs and an increase of $\geq 1$ complete SBM from baseline; or a combination of the two criteria. As secondary end points the 12-week change-from-baseline of worst abdominal pain, abdominal discomfort, abdominal bloating, stool 


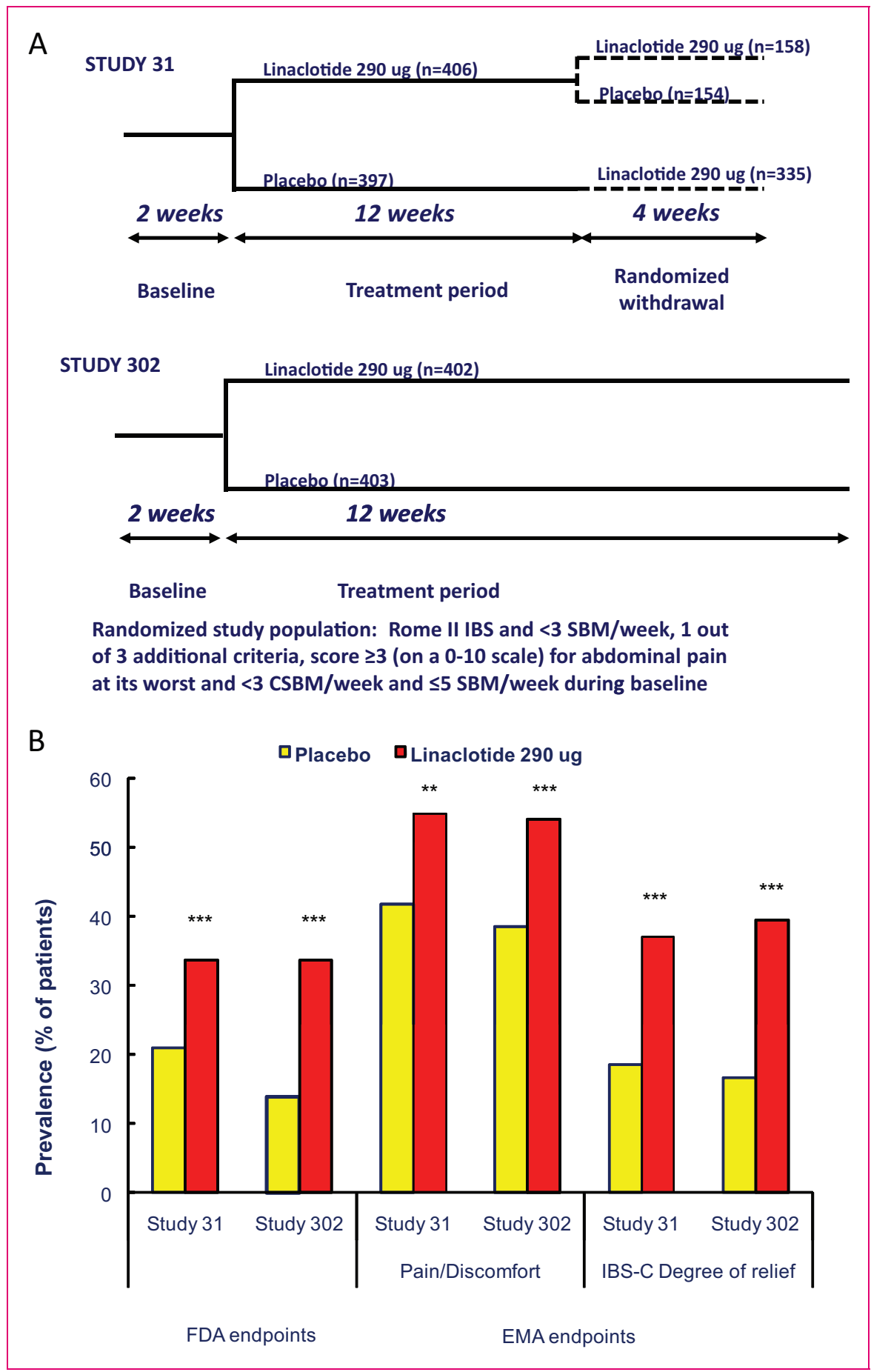

Figure 3. (A) Schematic outline of the phase III studies with linaclotide in irritable bowel syndrome (IBS) with constipation. SBM: spontaneous bowel movement; CSBM: complete spontaneous bowel movement. (B) Responder rates to placebo and linaclotide $290 \mu \mathrm{g}$ in studies 31 and 302 in IBS with constipation, according to the Food and Drug administration (FDA) and European Medicines Agency (EMA) guidelines. Left part of the graph: according to FDA guidelines, responders have to be both abdominal pain and bowel movement responders. Abdominal pain responders are defined as patients with a reduction of $\geq 30 \%$ in worst abdominal pain for $\geq 6 / 12$ first weeks of treatment, and responders for bowel movements are defined as patients with an increase $\geq 1$ CSBM from baseline for $\geq 6 / 12$ first weeks of treatment. Right part of the graph: according to EMA guidelines, abdominal pain/discomfort responders are defined as patients with a reduction of $\geq 30 \%$ in worst abdominal pain score or mean abdominal discomfort score for that week, with neither of these scores worsening from baseline for that week for $\geq 6 / 12$ weeks, and IBS degree-of-relief responders were defined as patients whose response to the degree-of-relief of IBS symptoms question was "considerably relieved" or "completely relieved" (i.e. a score of 1 or 2 ) for $\geq 6 / 12$ first weeks of treatment. ${ }^{\star} p<0.01$ compared to placebo; ${ }^{\star \star} p<0.001$ compared to placebo; ${ }^{\star \star \star} p<0.0001$ compared to placebo. 
frequency, stool consistency and severity of straining were considered. In study 302 the primary and secondary end points were also evaluated over the 26 weeks of treatment. The majority of patients in the two studies were females, with a mean number of SBMs of about two per week and of complete SBM of about 0.2 per week with constipation and IBS severity scores, respectively, of about 3.8 and 3.7 during the run-in period.

In study 31 , the FDA end point was met by $33.6 \%$ of linaclotide-treated patients compared to the $21 \%$ of placebo-treated patients, resulting in a number needed to treat (NNT) of $8^{23}$ (Figure 3B). A greater percentage of patients treated with linaclotide compared to those treated with placebo were also responders for the other three primary end points and for the secondary end points. The response to linaclotide started during the first week of treatment for both bowel symptoms and bowel function, but while it was maximal for bowel function in the first week, it did not seem to reach the maximal effect for abdominal pain before the sixth week of treatment, or even later. During the RW period patients remaining on linaclotide showed sustained improvement, those who were re-randomised from linaclotide to placebo showed a return of symptoms but without worsening of symptoms relative to baseline. Diarrhrea was again the most frequent adverse event resulted in discontinuation of linaclotide in $5.7 \%$ versus $0.3 \%$ of cases with placebo. The onset of diarrhea was mainly during the first two weeks of treatment and was reported as mild to moderate. In this study abdominal pain and flatulence were also reported significantly more frequently as adverse event during linaclotide than during placebo treatment. No serious side effects were reported more frequently with linaclotide than with placebo.

In study 302 , the FDA end point was met by $33.7 \%$ of linaclotide-treated patients compared to $13.9 \%$ of placebo-treated patients, resulting in a NNT of $5 .{ }^{24} \mathrm{~A}$ greater percentage of patients treated with linaclotide compared to those treated with placebo were also responders for the other three primary end points and for the secondary end points. The response to linaclotide started during the first week of treatment for both bowel symptoms and bowel function but while it was maximal for bowel function in the first week, the maximal effect for abdominal pain was only reached around eight weeks of treatment. The differences from placebo were continuous over the 26 weeks of treatment. Diarrhea was the more frequent adverse event and in most patients occurred during the first weeks of treatment. The severity of diarrhea was generally reported as mild to moderate and patients tolerated this adverse event as evidenced by the relatively low rate of discontinuation (linaclotide $4.5 \%$ versus placebo $0.2 \%$ ). No serious side effects were reported more frequently with linaclotide than with placebo.
Phase III, EMA end points. The results of the two phase III studies on C-IBS have been also evaluated according to the pre-specified endpoints for EMA submission. ${ }^{25,45}$ The EMA co-primary endpoints were (1) 12-week abdominal pain/discomfort responders (a patient who, for at least six weeks out of the first 12 weeks of treatment, had an improvement of $30 \%$ or more from baseline in either mean worst abdominal pain score or mean abdominal discomfort for that week, with neither of these scores worsening from baseline for that week) and(2) 12-week IBS degree-of-relief responders (a patient whose response to the degree-of-relief of IBS symptoms question was "considerably relieved" or "completely relieved" for at least six weeks out of the first 12 weeks of treatment). As another secondary end point the 26-week abdominal pain/discomfort responders and 26-week IBS degree-of-relief responders (responders for at least 13 weeks out of 26 weeks of treatment) as well as the sustained responders (patients who met the co-primary endpoints and were responders for at least two of the last weeks of treatment were assessed. Additional secondary end points were the health outcomes included in the Irritable Bowel Syndrome-Quality of Life (IBS-Qol) and in the EuroQol-5 Dimensions (EQ-5D) instruments and all the secondary end points already included in the FDA submission. The results demonstrated that a greater proportion of linaclotide-treated versus placebo-treated patients were 12-week abdominal pain/discomfort responders (study $31: 54.8 \%$ vs. $41.8 \%$; study 302: $54.1 \%$ vs. $38.5 \%$ ), 12 -week IBS degree-of-relief responders (study $31: 37 \%$ vs $18.5 \%$; study 302 $39.4 \%$ vs. $16.6 \%$ ), 26 -week pain/discomfort responders $(53.6 \%$ vs. $36 \%)$ and 26-week IBS degree-of-relief responders $(37.2 \%$ vs. $16.9 \%)$ (Figure $3 \mathrm{~B})$. In the same way, a greater proportion of linaclotide-treated versus placebo-treated patients were 12-week and 26week pain/discomfort and IBS degree-of-relief sustained responders. Compared to placebo, linaclotide was associated with significant improvement of all the secondary endpoints, including bloating severity and health outcomes, not reported in the FDA submission.

More than $2100 \mathrm{C}$-IBS patients entered a 12-month open-label safety study of up to one year's treatment with 145 or $290 \mu \mathrm{g}$ daily. The most frequently reported adverse event was diarrhea, occurring in $30.4 \%$ of the patients, and rated as severe in $3.0 \%$. No other major adverse events were noted. ${ }^{40,41}$

\section{Clinical perspective}

Chronic constipation and IBS with constipation are highly prevalent conditions, with considerable overlap between both of them. ${ }^{1,13}$ Until recently, treatment options for these conditions have focused on individual 
(predominant) symptoms, using laxatives for constipation in CC and C-IBS, and spasmolytic agents for pain and discomfort in C-IBS. ${ }^{46} \mathrm{~A}$ recent European multicenter study confirmed the efficacy of the musculotropic spasmolytic agent otilonium bromide in improving abdominal pain and bloating, but no significant effect on stool pattern was obtained. ${ }^{47}$ The serotonin-4 receptor was the first target that provided the ability to address the overall symptom complex in $\mathrm{CC}$ and C-IBS. ${ }^{48-53}$ Tegaserod was approved in most parts of the world outside Europe, but was later withdrawn for cardiovascular safety issues which have been attributed to lack of pharmacological selectivity. ${ }^{54}$ Prucalopride, a highly selective 5-HT4 agonist, was developed for the treatment of CC and has been approved in several parts of the world for the treatment of patients with chronic constipation who fail to respond to laxatives. ${ }^{55-58}$ To date, the drug has not been approved in the United States, and no studies have been reported in C-IBS.

A second approach in CC and C-IBS has been the development of luminally acting secretagogues. The first molecule to be developed was lubiprostone, a lipophilic prostanoid compound which activates the $\mathrm{CCl}_{2}$ chloride channel on the luminal surface. In phase II and phase III studies, lubiprostone was shown to enhance colonic transit, increase the stool frequency, reduce stool consistency and straining in $\mathrm{CC}$ and in addition to reduce abdominal pain and improve bowel function in C-IBS (15-18). The drug is not currently approved in Europe and the main side effect, nausea, is often mild and transient, leading to withdrawal in $5 \%$ of patients.

Linaclotide was developed as a different type of luminally acting secretagogue, targeting the guanylate cyclase $\mathrm{C}$ of gastrointestinal epithelial cells and secondarily stimulating chloride secretion through the CFTR channel. ${ }^{31-33}$ Similar to lubiprostone linaclotide was shown to enhance colonic transit, increase stool frequency and reduce stool consistency and straining in CC. ${ }^{19,40}$ The side effect profile of linaclotide was favorable, with the main reported adverse event being diarrhea which was mostly mild and transient. Initial studies were performed with a dose range of 75,150 , 300 and $600 \mu \mathrm{g}$ daily, showing dose-dependent efficacy and the best tolerance profile for doses up to $300 \mu \mathrm{g} .{ }^{20}$ The phase III studies evaluated 145 and $290 \mu \mathrm{g}$ daily and showed comparable superiority to placebo in CC, leading to FDA approval of linaclotide $145 \mu \mathrm{g}$ daily for the treatment of $\mathrm{CC} .^{21}$ At present, linaclotide is only approved for CC in the United States, but with time it is likely that clinicians in some countries will have access to lubiprostone, prucalopride as well as linaclotide for the treatment of CC. The relative place of each of these novel drugs in the treatment algorithm remains to be determined. As CC is a heterogeneous condition in terms of underlying pathophysiology, it is not surprising that each of these drugs provided clinically meaningful benefit to roughly half of the patients in the clinical studies. Hence, none of these novel drugs alone is able to address the remaining unmet need in $\mathrm{CC}$, and the fact that they have different modes of action is an advantage. In the absence of direct comparator clinical trials, clinical experience may eventually help to determine which type of CC patient is most likely to benefit from the respective drug.

The efficacy of linaclotide was also extensively evaluated in patients with C-IBS. Based on the evaluation of the phase II program, the phase III studies evaluated $290 \mu \mathrm{g}$ daily versus placebo. ${ }^{22-24}$ The phase III studies were conducted in the United States, but were evaluated according to both FDA and EMA-specified end points. ${ }^{23-25}$ Both the FDA and EMA evaluate abdominal pain as a key outcome measure. For the EMA-end point analysis, severity of pain and discomfort were pooled together. In addition, FDA guidelines recommend also measuring stool frequency as a primary end point, while the EMA recommends evaluating overall IBS symptom severity. ${ }^{43-45}$ In theory, the EMA guidelines have the potential to better differentiate responsiveness in CC from responsiveness in C-IBS. The difference in the end point assessments from the same two pivotal trials is summarized in Figure 3B.

The FDA has already approved linaclotide for the treatment of C-IBS, and the EMA's Committee for Medicinal Products for Human Use has recommended authorization for the treatment of moderate to severe C-IBS. It may seem paradoxical that the dose approved for C-IBS is in fact higher than the approved dose for $\mathrm{CC}$. This is justified by the absence of significant gain of the $290 \mu \mathrm{g}$ dose over the $145 \mu \mathrm{g}$ dose in the CC phase III studies, and the greater gain in the C-IBS phase II studies with 300 over $150 \mu \mathrm{g}$. Taking into account the efficacy on the multiple aspects of the C-IBS symptom pattern, linaclotide offers a major improvement of the therapeutic abilities for C-IBS in Europe. In the United States, lubiprostone, which also acts as a luminally acting secretagogue, is also approved for the treatment of C-IBS. Again, no direct comparator clinical trials are available, but the available data suggest that linaclotide offers unique additional therapeutic benefit for the treatment of pain.

Indeed, the magnitude of improvement of abdominal pain (and bloating) (Figure 4) in the linaclotide C-IBS studies seems greater than observed in controlled trials in IBS to date. Preliminary analysis of the effects of linaclotide on stool pattern and on abdominal pain in C-IBS suggests that the former does not explain the latter. ${ }^{59}$ Animal research identified beneficial effects of GC-C activation on visceral hyperalgesia through the generation of cyclic GMP. It has been suggested that similar mechanisms contribute to the beneficial effects 


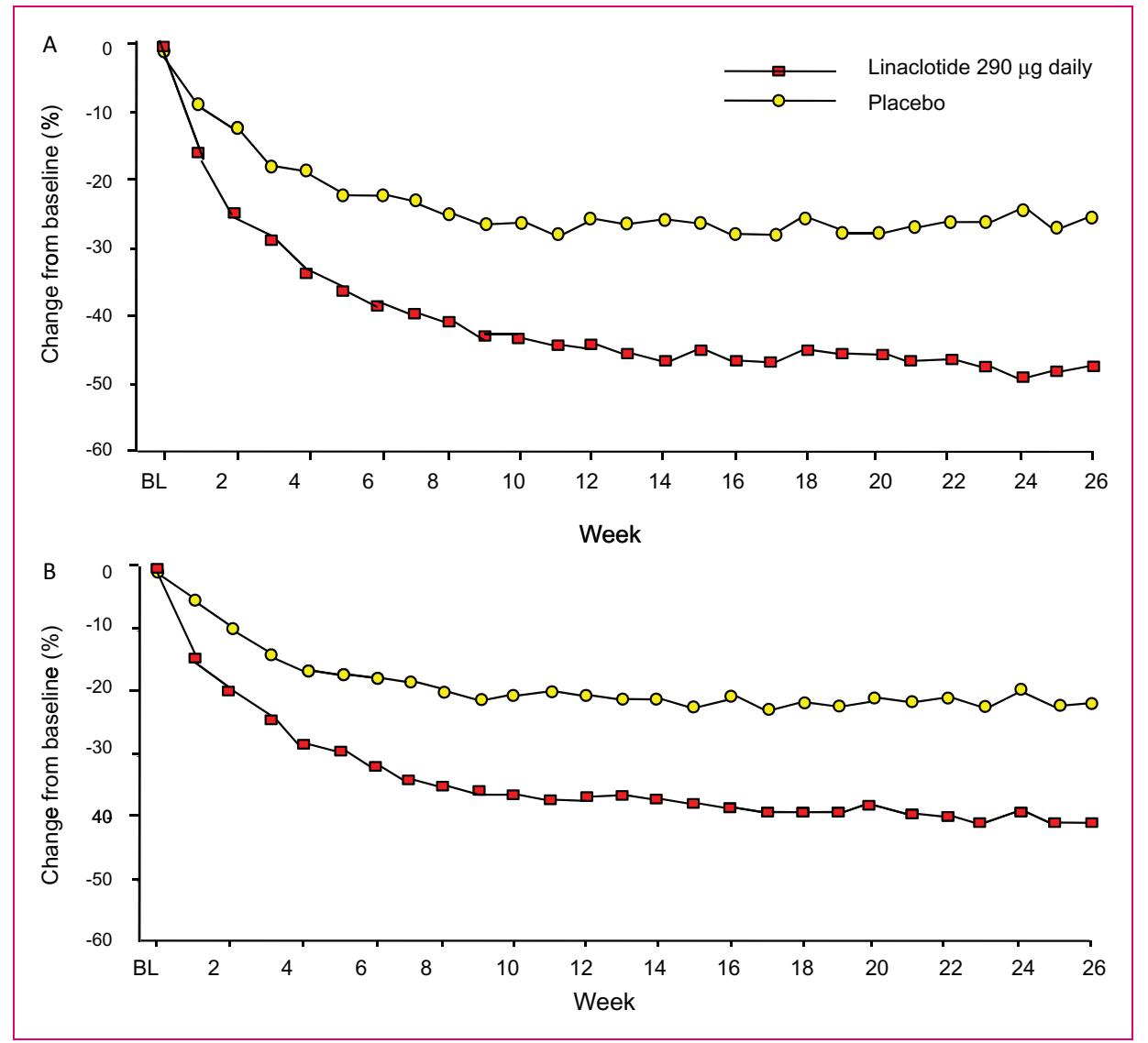

Figure 4. (A) Weekly change from baseline in worst abdominal pain rating in study 302 . Worst abdominal pain was assessed daily on a $0-10$ scale and percentage change was calculated as weekly change multiplied by 100 , divided by baseline score. $p<0.0001$ (linaclotide versus placebo, generalized linear model analysis of covariance), modified from Chey et al. ${ }^{24}$ (B) Weekly change from baseline in bloating severity in study 302 (intent-to-treat population, observed cases). Bloating was assessed daily on a 0-10 scale and percentage change was calculated as weekly change multiplied by 100 , divided by baseline score. $p<0.0001$ (linaclotide versus placebo, generalised linear model analysis of covariance), modified from Quigley et al. ${ }^{25}$

of linaclotide on pain ratings in C-IBS. On the other hand, the animal studies are acute studies while the improvement of pain in the IBS studies occurs gradually over the first six to eight weeks. Hence, the mechanism underlying the improvement of pain with linaclotide in C-IBS requires further studies.

Linaclotide is poorly absorbed and showed a favorable safety profile in the cinical trial program, with a low incidence of serious adverse events. However, the incidence of diarrhea (often transient and mild) is relatively high (up to $20 \%$ ), and the discontinuation rate may be up to $5 \%$. The use in clinical practice will have to further evaluate the significance of the transient diarrhea that may occur at the start of treatment, and the best strategies to minimize its impact. Linaclotide's effect on pain and discomfort, which seems to be at least in part independent from its effect on bowel movements, opens the avenue to exploring this and other guanylate cyclase agonist in other conditions, including functional dyspepsia and functional bloating.

\section{Conflict of interest}

The authors declare that there is no conflict of interest.

\section{Funding}

This research received no specific grant from any funding agency in the public, commercial, or not-for-profit sectors.

\section{References}

1. Suares NC and Ford AC. Prevalence of, and risk factors for, chronic idiopathic constipation in the community: systematic review and meta-analysis. Am J Gastroenterol 2011; 106(9): 1582-1591.

2. Lembo A and Camilleri M. Chronic constipation. $N$ Engl $J$ Med 2003; 349(14): 1360-1368.

3. Longstreth G, Thompson W, Chey W, et al. Functional bowel disorders. Gastroenterology 2006; 130(5): 1480-1491.

4. Sun SX, Dibonaventura M, Purayidathil FW, et al. Impact of chronic constipation on health-related quality of life, work productivity, and healthcare resource use: an analysis 
of the National Health and Wellness Survey. Dig Dis Sci 2011; 56(9): 2688-2695.

5. Irvine EJ, Ferrazzi S, Pare P, et al. Health-related quality of life in functional GI disorders: focus on constipation and resource utilization. Am J Gastroenterol 2002; 97(8): 1986-1993.

6. Wald A and Sigurdsson L. Quality of life in children and adults with constipation. Best Pract Res Clin Gastroenterol 2011; 25(1): 19-27.

7. Dennison C, Prasad M, Lloyd A, et al. The health-related quality of life and economic burden of constipation. Pharmacoeconomics 2005; 23(5): 461-476.

8. Tack J and Müller-Lissner S. Treatment of chronic constipation: current pharmacologic approaches and future directions. Clin Gastroenterol Hepatol 2009; 7(5): 502-508.

9. Wald A, Scarpignato C, Mueller-Lissner S, et al. A multinational survey of prevalence and patterns of laxative use among adults with self-defined constipation. Aliment Pharmacol Ther 2008; 28(7): 917-930.

10. Tack J. Current and future therapies for chronic constipation. Best Pract Res Clin Gastroenterol 2011; 25(1): $151-158$.

11. American College of Gastroenterology Chronic Constipation Task Force. An evidence-based approach to the management of chronic constipation in North America. Am J Gastroenterol 2005; 100: S1-4.

12. Tack J, Müller-Lissner S, Stanghellini V, et al. Diagnosis and treatment of chronic constipation-a European perspective. Neurogastroenterol Motil 2011; 23(8): 697-710.

13. Lovell RM and Ford AC. Global prevalence of and risk factors for irritable bowel syndrome: a meta-analysis. Clin Gastroenterol Hepatol 2012; 10(7): 712-721.

14. Tack J, Fried M, Houghton LA, et al. Systematic review: the efficacy of treatments for irritable bowel syndrome - a European perspective. Aliment Pharmacol Ther 2006; 24(2): 183-205.

15. Johanson JF, Morton D, Geenen J, et al. Multicenter, 4-week, double-blind, randomized, placebo-controlled trial of lubiprostone, a locally-acting type-2 chloride channel activator, in patients with chronic constipation. Am J Gastroenterol 2008; 103(1): 170-177.

16. Barish CF, Drossman D, Johanson JF, et al. Efficacy and safety of lubiprostone in patients with chronic constipation. Dig Dis Sci 2010; 55(4): 1090-1097.

17. Johanson JF, Drossman DA, Panas R, et al. Clinical trial: phase 2 study of lubiprostone for irritable bowel syndrome with constipation. Aliment Pharmacol Ther 2008; 27(8): 685-696.

18. Drossman DA, Chey WD, Johanson JF, et al. Clinical trial: lubiprostone in patients with constipation-associated irritable bowel syndrome-results of two randomized, placebo-controlled studies. Aliment Pharmacol Ther 2009; 29(3): 329-341.

19. Johnston JM, Kurtz CB, Drossman DA, et al. Pilot study on the effect of linaclotide in patients with chronic constipation. Am J Gastroenterol 2009; 104(1): 125-132.

20. Lembo AJ, Kurtz CB, Macdougall JE, et al. Efficacy of linaclotide for patients with chronic constipation. Gastroenterology 2010; 138(3): 886-895.
21. Lembo AJ, Schneier HA, Shiff SJ, et al. Two randomized trials of linaclotide for chronic constipation. $N$ Engl J Med 2011; 365(6): 527-536.

22. Johnston JM, Kurtz CB, Macdougall JE, et al. Linaclotide improves abdominal pain and bowel habits in a phase IIb study of patients with irritable bowel syndrome with constipation. Gastroenterology 2010; 139(6): 1877-1886.

23. Rao S, Lembo AJ, Shiff SJ, et al. A 12-week, randomized, controlled trial with a 4-week randomized withdrawal period to evaluate the efficacy and safety of linaclotide in irritable bowel syndrome with constipation. $\mathrm{Am} \mathrm{J}$ Gastroenterol Epub ahead of print 18 September 2012 DOI: 10.1038/ajg.2012.255.

24. Chey WD, Lembo AJ, Lavins BJ, et al. Linaclotide for irritable bowel syndrome with constipation: a 26-week, randomized, double-blind, placebo-controlled trial to evaluate efficacy and safety. Am J Gastroenterol Epub ahead of print 18 September 2012 DOI: 10.1038/ajg.2012.254.

25. Quigley EM, Tack J, Chey WD, et al. Randomised clinical trials: linaclotide phase 3 studies in IBS-C - a prespecified further analysis based on European Medicines Agency-specified endpoints. Aliment Pharmacol Ther 2013; 37(1): 49-61.

26. Field M, Graf Jr LH, Laird WJ, et al. Heat-stable enterotoxin of Escherichia coli: in vitro effects on guanylate cyclase activity, cyclic GMP concentration, and ion transport in small intestine. Proc Natl Acad Sci USA 1978; 75(6): 2800-2804.

27. Hughes JM, Murad F, Chang B, et al. Role of cyclic GMP in the action of heat-stable enterotoxin of Escherichia coli. Nature 1978; 271(5647): 755-756.

28. Currie MG, Fok KF, Kato J, et al. Guanylin: an endogenous activator of intestinal guanylate cyclase. Proc Natl Acad Sci USA 1992; 89(3): 947-951.

29. Hamra FK, Forte LR, Eber SL, et al. Uroguanylin: structure and activity of a second endogenous peptide that stimulates intestinal guanylate cyclase. Proc Natl Acad Sci USA 1993; 90(22): 10464-10468.

30. Potter LR. Regulation and therapeutic targeting of peptide-activated receptor guanylyl cyclases. Pharmacol Ther 2011; 130(1): 71-82.

31. Busby RW, Bryant AP, Bartolini WP, et al. Linaclotide, through activation of guanylate cyclase $\mathrm{C}$, acts locally in the gastrointestinal tract to elicit enhanced intestinal secretion and transit. Eur J Pharmacol 2010; 649(1-3): 328-335.

32. Bryant AP, Busby RW, Bartolini WP, et al. Linaclotide is a potent and selective guanylate cyclase $\mathrm{C}$ agonist that elicits pharmacological effects locally in the gastrointestinal tract. Life Sci 2010; 86(19-20): 760-765.

33. Busby RW, Kessler MM, Bartolini WP, et al. Pharmacological properties, metabolism and disposition of linaclotide, a novel therapeutic peptide approved for the treatment of irritable bowel syndrome with constipation and chronic idiopathic constipation. J Pharmacol Exp Ther Epub ahead of print 22 October 2012.

34. Eutamene H, Bradesi S, Larauche M, et al. Guanylate cyclase C-mediated antinociceptive effects of linaclotide 
in rodent models of visceral pain. Neurogastroenterol Motil 2010; 22(3): 312-e84.

35. Castro J, Harrington AM, Hugher PA, et al. Mechanism of action for linaclotide induced abdominal pain relief. Gastroenterology 2012; 142;5(Suppl 1): 699.

36. Brierley SM. Guanylate cyclase-C receptor activation: unexpected biology. Curr Opin Pharmacol 2012; 12(6): 632-640.

37. Castro J, Martin C, Hughers PA, et al. A Novel role of cyclic GMP in colonic sensory neurotransmission in Healthy and TNBS-treated mice. Gastroenterology 2011; 140(5 Suppl. 1): 538.

38. Tonini $\mathrm{M}$ and Pace F. Drugs acting on serotonin receptors for the treatment of functional GI disorders. Dig Dis 2006; 24(1-2): 59-69.

39. Johnston J and Schneier HA. Clarification of trial end points presented in a recent review of linaclotide. Expert Rev Gastroenterol Hepatol 2012; 6(1): 13-14.

40. Studies NCT00765999 and NCT00730171, http:// www.clinicaltrials.gov/ct2/show/NCT00765999?term = linaclotide\&rank $=6$ and http://www.clinicaltrials.gov/ ct2/show $/$ NCT00730171?term $=$ linaclotide \&rank $=9$

41. http://www.fda.gov/downloads/Drugs/Guidance ComplianceRegulatoryInformation/Guidances/ UCM205269.pdf

42. Andresen V, Camilleri M, Busciglio IA, et al. Effect of 5 days linaclotide on transit and bowel function in females with constipation-predominant irritable bowel syndrome. Gastroenterology 2007; 133(3): 761-768.

43. Trentacosti AM, He R, Burke LB, et al. Evolution of clinical trials for irritable bowel syndrome: issues in end points and study design. Am J Gastroenterol 2010; 105(4): 731-735.

44. U.S. Department of Health and Human Services, Food and Drug Administration, Center for Drug Evaluation and Research (CDER). Guidance for industry, irritable bowel syndrome, clinical evaluation of drugs for treatment, http://www.fda.gov/downloads/Drugs/Guidance ComplianceRegulatoryInformation/Guidances/UCM205 269.pdf.

45. European Medicines Agency. EMA guideline on irritable bowel syndrome (IBS). CPMP/EWP/785/97 (http://www. ema.europa.eu/docs/en_GB/document_library/ Scientific_guideline/2009/09/WC500003187.pdf, March 2003).

46. Camilleri M and Tack JF. Current medical treatments of dyspepsia and irritable bowel syndrome. Gastroenterol Clin North Am 2010; 39(3): 481-493.

47. Clavé P, Acalovschi M, Triantafillidis JK, et al; OBIS Study Investigators. Randomised clinical trial: otilonium bromide improves frequency of abdominal pain, severity of distention and time to relapse in patients with irritable bowel syndrome. Aliment Pharmacol Ther 2011; 34(4): 432-442.
48. Novick J, Miner P, Krause R, et al. A randomized, double-blind, placebo-controlled trial of tegaserod in female patients suffering from irritable bowel syndrome with constipation. Aliment Pharmacol Ther 2002; 16(11): 1877-1888.

49. Nyhlin H, Bang C, Elsborg L, et al. A double-blind, placebo-controlled, randomized study to evaluate the efficacy, safety and tolerability of tegaserod in patients with irritable bowel syndrome. Scand $J$ Gastroenterol 2004; 39(2): 119-126.

50. Johanson JF, Wald A, Tougas G, et al. Effect of tegaserod in chronic constipation: a randomized, doubleblind, controlled trial. Clin Gastroenterol Hepatol 2004; 2(9): 796-805.

51. Kamm MA, Müller-Lissner S, Talley NJ, et al. Tegaserod for the treatment of chronic constipation: a randomized, double-blind, placebo-controlled multinational study. Am J Gastroenterol 2005; 100(2): 362-372.

52. Tack J, Müller-Lissner S, Bytzer P, et al. A randomised controlled trial assessing the efficacy and safety of repeated tegaserod therapy in women with irritable bowel syndrome with constipation. Gut 2005; 54(12): 1707-1713.

53. Tack J, Camilleri M, Chang L, et al. Systematic review: cardiovascular safety profile of 5-HT(4) agonists developed for gastrointestinal disorders. Aliment Pharmacol Ther 2012; 35(7): 745-767.

54. De Maeyer JH, Lefebvre RA and Schuurkes JA. 5-HT4 receptor agonists: similar but not the same. Neurogastroenterol Motil 2008; 20(2): 99-112.

55. Camilleri M, Kerstens R, Rykx A, et al. A placebo-controlled trial of prucalopride for severe chronic constipation. $N$ Engl J Med 2008; 358(22): 2344-2354.

56. Tack J, van Outryve M, Beyens G, et al. Prucalopride (Resolor) in the treatment of severe chronic constipation in patients dissatisfied with laxatives. Gut 2009; 58(3): 357-365.

57. Quigley EM, Vandeplassche L, Kerstens R, et al. Clinical trial: the efficacy, impact on quality of life, and safety and tolerability of prucalopride in severe chronic constipation - a 12-week, randomized, double-blind, placebo-controlled study. Aliment Pharmacol Ther 2009; 29(3): 315-328.

58. Ke M, Zou D, Yuan Y, et al. Prucalopride in the treatment of chronic constipation in patients from the AsiaPacific region: a randomized, double-blind, placebo-controlled study. Neurogastroenterol Motil 2012; 24(11): 999-e541.

59. MacDougall JE, MacKinnon DP, Lavins BJ, et al. Mediation analysis suggests that linaclotide has a direct effect on relief of abdominal pain independent of constipation improvement. Neurogastroenterol Motil 2012; 24(Suppl. 2): 180-181. 